\title{
PENGARUH PEMBERIAN FUNCTIONAL ELECTRICAL STIMULATION TERHADAP SKALA NYERI SUBLUKSASI SHOULDER PADA PASIEN POST STROKE DI RUMAH SAKIT GRANDMED LUBUK PAKAM
}

\section{SABIRIN BERAMPU1 ${ }^{1}$, IRAMANDA SARI BERAMPU ${ }^{2}$, ISIDORUS JEHAMAN ${ }^{3}$}

\author{
${ }^{1}$ PROGRAM STUDI FISIOTERAPI FAKULTAS KEPERAWATAN DAN FISIOTERAPI \\ INSTITUT KESEHATAN MEDISTRA LUBUK PAKAM \\ JL. SUDIRMAN NO.38 LUBUK PAKAM KEC. LUBUK PAKAM KAB. DELI \\ SERDANG, SUMATERA UTARA \\ Email: sabirinberampu@gmail.com
}

DOI $10.35451 / j k f . v 3 i 2.659$

\begin{abstract}
Science and innovation today become an indivisible piece of the innovation of present day culture's life. Utilitarian Electrical Incitement (FES) to help recuperation of upper appendage after stroke. This examination is a quantitative exploration with a semi exploratory/semi trial way to deal with the exploration configuration utilizing pre-test and post-test. Assurance of the quantity of tests utilizing the Purposive Inspecting strategy and get an example of 12 individuals. Information assortment was done by direct meeting utilizing perception sheets. The free factor in this investigation is Useful Electrical Incitement (FES) while the reliant variable is the Shoulder Subluxation Agony Scale. The appraisal of shoulder subluxation torment scale incorporates a less than overwhelming agony scale class of 6 individuals (half), and moderate torment 4 individuals (33.3\%) and exceptionally serious torment 2 individuals (16.7). Factual test utilizing Matched Example T-test with $a=0.05$. The aftereffects of the examination show that there is a critical impact between the arrangement of Practical Electrical Incitement (FES) on the size of shoulder torment subluxation in post-stroke patients, ie with a $p$ esteem (0.001 0.05$)$. The finish of this investigation is that there is an impact between Useful Electrical Incitement (FES) with Shoulder Subluxation Agony. Exhortation can be given is normal for post stroke patients and family backing to focus on the patient's repetitive resting position.
\end{abstract}

Keywords: Functional Electrical Stimulation, Post Stroke, Shoulder Subluxation 


\section{PENDAHULUAN}

Kemajuan peradaban masyarakat semakin berkembang pesat di segala bidang kehidupan. Ilmu pengetahuan dan teknologi dewasa ini menjadi bagian yang tidak terpisahkan dari teknologi kehidupan masyarakat. Kesibukan yang luar biasa terutama di kota besar membuat masyarakat terkadang mengabaikan kesehatan mereka. Pola makan tidak teratur, kurang olah raga, jam kerja berlebihan dan konsumsi reasonable food (makan cepat saji) Ini sudah menjadi kebiasaan umum yang bisa menyebabkan stroke. Stroke terjadi akibat pembuluh darah yang membawa darah dan oksigen ke otak mengalami penyumbatan atau ruptur, hipoksia menyebabkan fungsi kontrol Gerakan tubuh yang dikendalikan oleh otak tidak berfungsi karena sel syaraf mengalami infark atau nekrosis (Dinata et al 2012).

Stroke merupakan penyebab kecacatan nomor satu di dunia dan penyebab kematian nomor tiga di dunia setelah penyakit jantung dan kanker. Berdasarkan data Setiap tahun 15 juta orang di seluruh dunia terserang stroke, dan sepertiga dari mereka meninggal Sisanya mengalami cacat permanen (American Heart Connection, 2015). Stroke Ini adalah penyebab cacat parah nomor satu, dan masih ada di seluruh dunia. Di Indonesia, masalah stroke menjadi semakin penting karena penyakit stroke di Indonesia banyak di negara-negara Asia (Yastroki, 2013). Menurut data Yayasan Stroke Indonesia (Yastroki), masalah stroke semakin meningkat dan mendesak karena jumlah penderita stroke di Indonesia semakin meningkat Insidensinya atau tingkat kejadiannya meningkat dan menjadi negara terbesar di Asia.

Subluksasi adalah komplikasi umum pasca stroke. Nyeri bahu dapat menyebabkan kecacatan yang signifikan yang dapat membatasi kemampuan pasien untuk mencapai potensi fungsional maksimal dan menghambat rehabilitasi (Suethanapornkul and Kuptniratsaikul, 2008). Menurut Smith et al (2018) Potensi teknologi Functional Electrical Stimulation (FES) untuk mendukung pemulihan ekstremitas atas setelah stroke. FES adalah sistem berbasis klinik yang dirancang untuk menggunakan stimulasi listrik, dapat digunakan pada otot-otot yang lemah atau lumpuh pasca stroke. Metode ini biasanya digunakan pada pergerakan sendi utama di tungkai atas, bahu, siku, sendi radio-ulnar, dan pergelangan tangan, yang dapat dikontrol menggunakan FES.

\section{METODE PENELITIAN}

Penelitian ini merupakan penelitian kuantitatif dengan pendekatan semi eksperimen dengan desain penelitian menggunakan pre test (sebelum) dan post test (sesudah) yaitu penelitian yang menjelaskan pengaruh Functional Electrical Stimulation (FES) terhadap peningkatan skala nyeri subluksasi shoulder pada penderita frozen shoulder di Poli Fisioterapi Rumah Sakit Grandmed Lubuk Pakam. seluruh pasien yang menderita nyeri subluksasi post stroke di Poli Fisioterapi Rumah Sakit Grandmed Lubuk Pakam, Dari bulan Januari sampai bulan Maret yaitu terdapat 20 orang penderita nyeri subluksasi shoulder post stroke. Pengambilan sampel dengan menggunakan tekhnik Purposive examining yaitu berdasarkan kriteriakriteria atau pertimbangan tertentu (Saryono, dkk. 2013). Pengumpulan data dengan menggunakan data primer dan data sekunder. Lembar Observasi dilakukan kepada responden dengan berpedoman pada lembar observasi yang telah dipersiapkan merupakan teknik yang digunakan dalam mengumpulkan data. Sedangkan data 
sekunder diperoleh melalui data yang terkait pasien penderita nyeri subluksasi post stroke dari bagian Administrator Poli Fisioterapi di Rumah Sakit GrandMed Lubuk Pakam yaitu, Setelah data terkumpul kemudian diolah dengan menggunakan uji combined example $t$-test dengan tingkat kepercayaan 95\% (alpha=5\%). Dasar pengambilan keputusan dengan ketentuan jika nilai $\mathrm{p}<\mathrm{a}$ maka $\mathrm{Ho}$ ditolak yang dapat disimpulkan bahwa terdapat hubungan antara variabel.

\section{HASIL}

Tabel 1. Distribusi Responden Berdasrkan Karakteristik Jenis Kelamin Pada Pasien Subluksasi Shoulder Post Stroke

\begin{tabular}{lcc}
\hline \multicolumn{1}{c}{ Karakteristik } & $\mathbf{n}$ & $\mathbf{\%}$ \\
\hline Jenis Kelamin & & \\
Laki-Laki & 6 & $50 \%$ \\
Perempuan & 6 & $50 \%$ \\
\hline \multicolumn{1}{c}{ Total } & $\mathbf{1 2}$ & $\mathbf{1 0 0 \%}$ \\
\hline
\end{tabular}

Tabel 1 di atas menunjukkan jumlah responden berdasarkan jenis kelamin laki-laki adalah berjumlah 6 orang (50 $\%)$, jumlah responden berdasarkan jenis kelamin perempuan adalah berjumlah 6 orang (50\%).

Tabel 2 Distribusi Frekuensi Rerata Skala Nyeri Sebelum Dan Sesudah Intervensi penggunaan Functional Electrical Stimulatio (FES) Terhadap Skala Nyeri Subluksasi Shoulder Pada Pasien Post

\begin{tabular}{llcc}
\hline No & Skala Nyeri & Min & Max \\
\hline 1 & Sebelum & & \\
& $\begin{array}{l}\text { Functional } \\
\text { Electrical } \\
\text { Stimulation }\end{array}$ & 4 & 8 \\
2 & $\begin{array}{l}\text { (FES) } \\
\text { Sesudah } \\
\text { Functional } \\
\text { Electrical } \\
\text { Stimulation } \\
\text { (FES) }\end{array}$ & 3 & 7 \\
\hline
\end{tabular}

Tabel 2. menunjukan bahwa skala nyeri negligible yang dirasakan responden sebelum intervensi (FES) adalah 4 dan maksimal adalah 8, Sedangkan skala nyeri yang dirasakan responden sesudah intervensi (FES) adalah 3 dan nyeri makisimal adalah 7 .

Tabel 3. Rerata Nyeri Sebelum Dan Sesudah Pemberian Intervensi

Functional Electrical Stimulation (FES)

Terhadap Skala Nyeri Subluksasi

Shoulder Pada Pasien Post Stroke

\begin{tabular}{lccc}
\hline \multicolumn{1}{c}{ Total } & Mean & $\begin{array}{c}\text { Std.De } \\
\text { viasi }\end{array}$ & $\begin{array}{c}\boldsymbol{p} \\
\text { value }\end{array}$ \\
\hline Total Pretest- & 1,250 & 0,965 & 0,001 \\
Total postest & & & \\
\hline
\end{tabular}

Tabel 3.menunjukkan bahwa perbedaan nilai rata-rata nyeri antara pengukuran sebelum (Pre Test) dan sesudah (Post Test) yaitu 1,250 dengan standart deviasi 0,965.

\section{PEMBAHASAN}

Berdasarkan hasil penelitian sebelum dilakukan pemberian FES diketahui responden merasakan nyeri yang hebat sebelum dilakukan intervensi FES yaitu nilai nyeri skala 4 nilai dan sesudah didapatkan nilai skala 8.

Berdasarkan hasil penelitian sesudah dilakukan pemberian Functional Electrical Stimulation (FES) di ketahui rata-rata dan maximal skala nyeri yang di rasakan responden sesudah dilakukan intervensi Functional Electrical Stimulation (FES) adalah 3 nilai sebelum dan nilai sesudah 7 .

Berdasarkan hasil penelitian (Hughes et al., 2018) Tindakan yang dilakukan dengan mengunakan FES menghasilkan peningkatan yang lebih besar pada penderita nyeri subluksasi shoulder terhadap pengurangan nyeri dengan menggunakan alat ukur NRS. 
Ketika sudah terjadinya nyeri maka pasien secara otomatis akan melakukan pertahanan diri dengan mengurangi pergerakan pada daerah shoulder yang menyebabkan nyeri, akibatnya caput pada persendian glenohumeral akan semakin bergeser sehingga nyeri akan timbul. Apabila pergeseran tersebut secara terusmenerus terjadi akan mengakibatkan responden tidak dapat menggerakkan shoulder dengan secara normal, oleh karena itu penanganan secara dini harus segera dilakukan Fisioterapi. Berdasarkan hasil penelitian (Faghri et al., 2016) penanganan yang dilakukan dengan menggunakan (FES) telah terbukti menghasilkan penyembuhan yang lebih besar pada penderita nyeri subluksasi shoulder menunjukkan penurunan $\quad(p 0,001) \quad$ dengan mengunakan alat ukur NRS.

Berdasarkan hasil penelitian diperoleh bahwa hasil pengukuran 12 responden sebelum diberikan pemberian diberikan (FES) menunujukkan skala nyeri ringan 4 orang $(33.3 \%)$, nyeri sedang 4 orang $(33.3 \%)$, nyeri berat 4 orang $(33,3 \%)$ dan setelah pemberian intervensi (FES) terhadap skala nyeri subluksasi shoulder selama $8 \mathrm{x}$ terapi dalam 4 minggu di peroleh skala nyeri ringan 6 orang, dan nyeri sedang 4 orang $(33,3 \%)$ dan nyeri sangat hebat 2 orang $(16,7)$. Berdasarkan pengolahan data yang telah dilakukan uji statistik dengan menggunakan uji combined example $t$-test, maka hasil pengolahan nyeri sebelum dan sesudah pemberian (FES), yaitu mean 1,250 dengan SD = 0,965 dan $p(0,001) \leq a(0,05)$, Kesimpulan dari penelitian ini adalah ada pengaruh (FES) terhadap skala nyeri subluksasi shoulder pada pasien post stroke Di Rumah Sakit Grandmed Lubuk Pakam.

\section{KESIMPULAN}

Kesimpulan pada penelitian ini yaitu:

a. Karakteristik responden berdasarkan jenis kelamin jumlah respondenlaki-laki adalah sebanyak 6 orang (50\%), jumlah responden berdasarkan jenis kelamin perempuan adalah sebanyak 6 orang (50\%) sebanyak 12 orang .

b. Rerata skala nyeri yang dirasakan responden sebelum pemberian intervensi (FES) adalah 4 dan maksimal adalah 8, Sedangkan skala nyeri yang dirasakan responden sesudah diberikan intervensi Functional Electrical Stimulatio (FES) adalah 3 dan nyeri maksimal adalah 7.

c. Ada pengaruh Functional Electrical Stimulation (FES) terhadap skala nyeri subluksasi shoulder pada pasien post stroke Di Rumah Sakit Grandmed Lubuk Pakam Tahun 2020 dengan nilai $\mathrm{p}(0,001) \leq \mathrm{a}$ $(0,05)$.

\section{DAFTAR PUSTAKA}

American Heart Affiliation. (2015) Rules for the Early Administration of Patient With Intense Ischemic Stroke A Rule forHealthcare Professionals.

Anggraini, G. D., Septiyanti, S. what's more, Dahrizal, D. (2018) 'Scope Of Movement (ROM) Circular Hold dapat Meningkatkan Kekuatan Otot Ekstremitas Atas Pasien Stroke', Jurnal Ilmu dan Teknologi Kesehatan, 6(1), pp. 38- 48. doi: $10.32668 /$ jitek.v6i1.85.

Aras, M., Gokkaya, N., Comert, D., Kaya, A. and Cakci, A., 2004, 'Shoulder torment in Hemiplegia', American Diary of Actual Medication and Restoration 83, 713-719. doi.org/10.1097/01.PHM.00001387 39.18844 .88

Arya, K. N. et al. (2018) 'Recovery 
techniques for lessening shoulder subluxation in post-stroke hemiparesis: a methodical review*', Points in Stroke Restoration. Taylor and Francis, 25(1), pp. 68-81. doi: 10.1080/10749357.2017.1383712.

Bakara, D. M. also, Warsito, S. (2016) 'Latihan Scope of Movement (Rom) Pasif Terhadap Rentang Sendi Pasien Pasca Stroke', Thought Nursing Diary, 7(2), pp. 12-18.

Brault, M., Hootman, J., Helmick, C., Theis, K. and Shield, B., 2009, 'Habitats for and

counteraction: Commonness and most basic reasons for incapacity among adults - US, 2005', Dismalness and Mortality Week by week Report 58, 421-426.

Dinata, C. A., Safrita, Y. what's more, Sastri, S. (2012) 'Gambaran Faktor Risiko dan Tipe Stroke pada Pasien Rawat Inap di Bagian Penyakit Dalam RSUD Kabupaten Solok Selatan Periode 1 Januari 2010 - 31 Juni 2012', Jurnal Kesehatan Andalas, 2(2), pp. 5761. Accessible at: http://jurnal.fk.unand.ac.id/index.p hp/jka/article/see/119.'FACTORS CAUSING NON-HEMORRHAGIC STROKE AT THE AGE OF Youthful Grown-ups Hendrik' (2018), (December), pp. 293-301.

Faghri, P. D. et al. (2016) 'The Impacts of Useful Electrical on Shoulder Subluxation, Arm Capacity Recuperation, and ShoukIer Agony in Hemiplegic Stroke Patients', 75, pp. 73-79.

Freixes, O. et al. (2017) 'Shoulder useful electrical incitement during wheelchair impetus in spinal line injury subjects', Points in Spinal Line Injury Restoration, 23(2), pp. 168-173. doi: 10.1310/sci2302168.

Hankey, G., Spiesser, J., Hakimi, Z.,
Bego, G., Carita, P. and Gabriel, S., 2007, 'Rate, degree, and indicators of recuperation from inability following ischemic stroke', Nervous system science 68, 15831587.

doi.org/10.1212/01.wnl.000026096 7. 77422.97 .

Hughes, A. M. et al. (2009) 'Achievability of iterative learning control intervened by useful electrical incitement for coming to after stroke', Neurorehabilitation and Neural Fix, 23(6), pp. 559568.

doi:

$10.1177 / 1545968308328718$.

Jensen, M. P. furthermore, Jensen, M. P. (2011) 'Estimating torment power', The agony stethoscope: A clinician's manual for estimating torment, pp. 3-7. doi: 10.1007/978-1-90851743-2_2.

Johnson, J. R. (2016) 'PhUSE 2016 Standard Strategies for Investigation and Announcing of VAS or NRS Inferred Relief from discomfort Reaction Scores', p. 14. Accessible at:

Junaidi Iskandar., (2011), Stroke waspadai ancamannya, Andi. Yogyakarta.

Jung, K. M. (2019) 'The Impacts of Dynamic Shoulder Exercise with a Sling Suspension Framework on Shoulder Subluxation, Proprioception, and Upper Extremity Capacity in Patients with Intense Stroke', pp. 4849-4855. doi: $10.12659 / M S M .915277$.

Laily, S. R. (2017) 'Pengetahuan dan Tindakan Pencegahan Penularan Penyakit Tuberkulosa Paru pada Keluarga Kontak Serumah', in Jurnal Berkala Epidemologi, pp. 85-94. doi: 10.20473/jbe.v5i1.

Mir, M. A., Al-Baradie, R. S. furthermore, Alhussainawi, M. D. (2014) Pathophysiology of Strokes. 
Murie-Fernández, M. et al. (2012) 'Hombro doloroso hemipléjico en pacientes con ictus: Causas y manejo', Neurologia. SEGO, 27(4), pp. 234-244. doi: ci, M.,

Nannetti, L. furthermore, Rinaldi, L. A. (2005) 'Glenohumeral subluxation in hemiplegia: An outline', Diary of Recovery Exploration and Development, 42(4), pp. 557568.doi:10.1682/JRRD.2004.08.01 12

Notoatmodjo, Soekidjo., (2012), Metodelogi penelitian kesehatan, Rineka Cipta, Jakarta.

Saryono, dkk. 2013. Metodologi Penelitian Kualitatif dan Kuantitatif Dalam Bidang Kesehatan, Yogyakarta: Nuha Medika.

Smith, C. et al. (2018) 'Expectation of arrangement times for a high level upper appendage functional electrical incitement framework', Diary of Recovery and Assistive Advances Designing, 5, p. $205566831880256 . \quad$ doi: $10.1177 / 2055668318802561$.

Stahmeyer, J. T. et al. (2019) 'Häufigkeit und Zeitpunkt von Rezidiven nach inzidentem Schlaganfall', Deutsches Arzteblatt Global, 116(42), pp. 711-717. doi: 10.3238/arztebl.2019.0711.

Suethanapornkul, S. furthermore, Kuptniratsaikul, P. S. (2008) 'Post Stroke Shoulder Subluxation and Shoulder Pain: An Accomplice Multicenter Study', 91(12), pp. 1885-1893.

Suharti, A., Sunandi, R. furthermore, Abdullah3, $F$.

'Penatalaksanaan Fisioterapi pada Frozen Shoulder Sinistra Terkait Hiperintensitas Labrum Back Superior di Rumah Sakit Pusat Angkatan Darat Gatot Soebroto', Jurnal Vokasi Indonesia, 6(1), pp. 51-65.

10.7454/jvi.v6i1.116.
Sulistyaningsih. 2011. Metodologi Penelitian Kesehatan Kebidanan Kuantitatif-Kualitatif. Yogyakarta: Graha IImu.

Suryawijaya, B. R., Rahmatillah, D. L. furthermore, Eff, A. R. (no date) 'Assessment OF Medication RELATED IsSues IN STROKE HEMORRHAGIC PATIENTS WITH Ongoing KIDNEY Sickness Complexities WHICH TREATED IN RSPAD GATOT SOEBROTO', 6, pp. 1627-1635.

Treister, A. K. et al. (2018) 'Demystifying post-stroke pain: from etiology to treatment', 9(1), pp. 63-75. doi: 10.1016/j.pmrj.2016.05.015.Demy stifying. 